\title{
Racial and socioeconomic disparities in the use of stereotactic body radiotherapy for treating non-small cell lung cancer: a narrative review
}

\author{
Yue Lin^, Kimberley S. Mak^ \\ Department of Radiation Oncology, Boston Medical Center, Boston University School of Medicine, Boston, USA \\ Contributions: (I) Conception and design: Both authors; (II) Administrative support: None; (III) Provision of study materials or patients: None; (IV) \\ Collection and assembly of data: Both authors; (V) Data analysis and interpretation: Both authors; (VI) Manuscript writing: Both authors; (VII) Final \\ approval of manuscript: Both authors. \\ Correspondence to: Kimberley Mak. Department of Radiation Oncology, Boston Medical Center, Boston University School of Medicine, Boston, USA. \\ Email: kimberley.mak@bmc.org.
}

\begin{abstract}
In the past two decades, there has been a steady increase in the use of stereotactic body radiotherapy (SBRT) as an alternative to surgical intervention for early-stage non-small cell lung cancer (NSCLC) patients; however, not much is known about the impact of race and socioeconomic status (SES) on the delivery of SBRT. Here, we conduct a narrative review to examine potential disparities in the use of SBRT. Keyword searches of MEDLINE/PubMed, Web of Science, Embase, and Google Scholar databases were performed for studies focused on race, SES, and the use of SBRT published between 2000 and 2020. Six studies were identified, and showed that minority patients, especially Blacks, were less likely to receive SBRT and had a significantly longer median time between diagnosis to SBRT treatment. Patients with lower income or lower education, as well as those from lower socioeconomic regions were less likely to receive SBRT; they were more likely to receive conventionally fractionated external beam radiation (CFRT) or no treatment. These racial and socioeconomic factors were associated with worse survival in other general earlystage NSCLC studies. In conclusion, the limited number of published studies suggest significant disparities in the treatment of early-stage NSCLC with SBRT. These factors potentially lead to worse survival outcomes among vulnerable patient populations. Equal access to SBRT should be a focus of healthcare delivery systems, to ensure optimal clinical outcomes for patients with early-stage NSCLC.
\end{abstract}

Keywords: Non-small cell lung cancer (NSCLC); disparities; stereotactic body radiotherapy (SBRT); socioeconomic; race

Submitted Oct 31, 2020. Accepted for publication Mar 04, 2021.

doi: $10.21037 /$ jtd-20-3199

View this article at: http://dx.doi.org/10.21037/jtd-20-3199

\section{Introduction}

\section{Rationale/background}

Lung cancer is the leading cause of cancer death in both males and females in the United States, accounting for almost one-quarter of all cancer deaths $(1,2)$. There are significant documented disparities in lung cancer prevalence and outcomes among individuals of different socioeconomic status (SES) (3). Several studies have documented that race and socioeconomic factors, such as income, education, and geographic location, are associated with differences in lung cancer prevalence as well as mortality (4-7). SES often manifests itself in one's health and access to care through differences in access to material and social resources,

^ ORCID: Yue Lin, 0000-0003-4143-174X; Kimberley S. Mak, 0000-0002-7388-5124. 
physical and emotional stressors, and health-related behaviors (8). SES may be an independent prognostic factor for survival in non-small cell lung cancer (NSCLC), with individuals living in low income areas having worse NSCLC survival than those residing in higher income areas, even after adjusting for stage of disease at presentation (9). With respect to racial and ethnic disparities, the incidence of lung cancer is higher in Black patients, and survival is lower in both Blacks and Hispanics compared to Whites (10). Minority patients are also more likely to present at advanced stages and less likely to receive any type of lung cancer treatment, including surgical resection, chemotherapy, or radiation therapy (11).

NSCLC is the most common type of lung cancer, and definitive surgical resection is generally the preferred treatment for patients with early-stage (Stage I-II) NSCLC (12-14). For the subset of patients who cannot undergo surgery due to pulmonary or cardiovascular function, other comorbidities, or personal preference, stereotactic body radiation therapy (SBRT) is increasingly considered a suitable and efficacious alternative (15-17). SBRT is a highly conformal, precise external beam radiation technique that delivers a very high biological effective dose of radiation (often defined as $>6 \mathrm{~Gy} /$ fraction) over a limited number of fractions (often five or less) (18). SBRT can lead to durable tumor response and is therefore known as "ablative" radiotherapy (19). SBRT has been shown to provide a high rate of local tumor control ( $>90 \%)$ in early-stage NSCLC (20-22). Compared to conventionally fractionated external beam radiation (CFRT), SBRT is associated with better survival outcomes and lower rates of toxicity (23). In addition to safety and efficacy, SBRT also offers increased convenience with a smaller number of treatments and visits needed, and has been shown to be cost-effective (20).

\section{Objectives}

Although SBRT has emerged over the last two decades as a promising therapy for early-stage NSCLC patients, not much is known about whether it is used equitably across different racial and socioeconomic groups. There are many studies examining the relationship between CFRT for NSCLC and SES (24-26), but these tend not to focus on SBRT. This comprehensive narrative review aimed to specifically focus on the impact of racial and socioeconomic disparities on the use of SBRT for lung cancer and clinical outcomes.

We present the following article in accordance with the Narrative Review Reporting Checklist (available at: http:// dx.doi.org/10.21037/jtd-20-3199).

\section{Methods}

\section{Research selection}

To identify studies on the association between race, socioeconomic factors and SBRT for lung cancer, four databases were used: MEDLINE/PubMed, Web of Science, Embase, and Google Scholar. The literature search focused on studies published from 2000 to October 12, 2020. A combination of key words related to socioeconomic determinants and SBRT was applied. Examples for these key words were: "socioeconomic," "disparity," "education," "income," "race," "ethnicity," "access," and/or "SBRT," "lung cancer," "stereotactic body radiation therapy", "radiotherapy." The inclusion criteria were (I) peer-reviewed academic journals published in English; (II) studies with a primary diagnosis of lung cancer reported separately from other cancers; (III) articles with accessible abstracts and full text. References cited in included studies were reviewed to identify additional studies. A forward citation search was also used to identify more recent studies that had cited the included studies.

\section{Study identification}

Six studies that analyze SBRT, race, and socioeconomic factors were identified (25-30). The studies are summarized in Table 1.

\section{Discussion}

\section{Racial and etbnic disparities in lung cancer SBRT access and outcomes}

In a retrospective National Cancer Database (NCDB) study of 113,312 Stage I NSCLC patients treated in 2003-2011, Corso et al. demonstrated that Black patients with earlystage NSCLC were not only less likely to receive surgery than White patients $(57.6 \%$ vs. $65.6 \%$; $\mathrm{P}<0.001)$, but also less likely to receive SBRT (5.5\% vs. $6.1 \%$; respectively, $\mathrm{P}<0.001)(27)$. Instead, Blacks were more likely to receive CFRT $(17.0 \%$ vs. $15.0 \%$; $\mathrm{P}<0.001)$ or no treatment $(19.9 \%$ vs. $13.3 \% ; \mathrm{P}<0.001)$ compared to Whites. Black patients were more likely to refuse any radiation treatment (both SBRT and CFRT) than White patients (2.2\% vs. $1.6 \%$ respectively; $\mathrm{P}<0.001)$. The authors also reported that a higher percentage of Black patients were uninsured and 
Table 1 Six identified studies that analyze associations between lung SBRT, race, and socioeconomic factors

\begin{tabular}{|c|c|c|c|c|c|c|}
\hline Author \& date & Title of article & $\begin{array}{l}\text { Number of } \\
\text { patients }\end{array}$ & $\begin{array}{l}\text { Study } \\
\text { period }\end{array}$ & $\begin{array}{l}\text { Data } \\
\text { source }\end{array}$ & $\begin{array}{l}\text { NSCLC } \\
\text { stage }\end{array}$ & $\begin{array}{l}\text { SES factors } \\
\text { examined }\end{array}$ \\
\hline Holmes et al. 2018 (25) & $\begin{array}{l}\text { Racial disparities in time from diagnosis } \\
\text { to treatment for stage I non-small cell } \\
\text { lung cancer }\end{array}$ & 119,184 & 2008-2013 & $\begin{array}{l}\text { National Cancer } \\
\text { Database (NCDB) }\end{array}$ & Stage I & Race \\
\hline Koshy et al. 2015 (26) & $\begin{array}{l}\text { Disparities in treatment of patients with } \\
\text { inoperable stage I non-small cell lung } \\
\text { cancer: A population-based analysis }\end{array}$ & 39,822 & 2003-2011 & NCDB & Stage I & Race, location \\
\hline Corso et al. 2015 (27) & $\begin{array}{l}\text { Racial disparities in the use of SBRT for } \\
\text { treating early-stage lung cancer }\end{array}$ & 113,312 & 2003-2011 & NCDB & Stage I & $\begin{array}{l}\text { Race, income, } \\
\text { education }\end{array}$ \\
\hline Rengan et al. 2014 (28) & $\begin{array}{l}\text { Impact of sociodemographic factors } \\
\text { on the radiotherapeutic management } \\
\text { of lung cancer: Results of a quality } \\
\text { research in radiation oncology survey }\end{array}$ & 340 & $2006-2007$ & $\begin{array}{l}45 \text { participating } \\
\text { institutions }\end{array}$ & Stage I-III & $\begin{array}{l}\text { Location, } \\
\text { income, } \\
\text { education }\end{array}$ \\
\hline Dalwadi et al. 2019 (30) & $\begin{array}{l}\text { Disparities in the treatment and outcome } \\
\text { of stage I non-small-cell lung cancer in } \\
\text { the } 21 \text { st century }\end{array}$ & 62,312 & 2004-2012 & $\begin{array}{l}\text { Surveillance, } \\
\text { Epidemiology, } \\
\text { and End Results } \\
\text { Database (SEER) }\end{array}$ & Stage I & Race \\
\hline
\end{tabular}

came from lower income and education areas. These factors could potentially further contribute to the barrier in SBRT access and lead to worse clinical outcomes. Moreover, the disparity in SBRT receipt between Black and White patients may be worsening with time. In 2006, the difference in SBRT use rate was only $0.2 \%$, but by 2011 , the difference increased to $2.3 \%$.

Similarly, in another NCDB study with 39,822 Stage I NSCLC patients who were treated with either radiotherapy or no treatment between 2003-2011, Koshy et al. demonstrated that Black Stage I NSCLC patients were less likely to receive any radiation therapy compared to Whites [odds ratio (OR) 0.64, 95\% CI, 0.60-0.69; $\mathrm{P}<0.001$ ], as were Hispanic patients (OR 0.42, 95\% CI, 0.36-0.49; $\mathrm{P}<0.001$ ) (26). Black patients were also less likely to receive SBRT than CFRT (OR 0.71, 95\% CI, 0.63-0.80; $\mathrm{P}<0.001$ ) compared to White patients.

In a third NCDB study of 23,088 NSCLC patients treated with either SBRT or CFRT between 2004-2015, Haque et al. confirmed on multivariable analysis that SBRT was less frequently delivered in Black patients compared to White patients (OR 0.79, 95\% CI, 0.66-0.94; P=0.008) (29). They also determined that on multivariate analysis adjusting for
SBRT vs. CFRT, Black patients continued to have worse overall survival [adjusted HR (aHR) 0.85, 95\% CI, 0.79-0.92; $\mathrm{P}<0.001]$.

In a SEER study of 62,312 Stage I NSCLC patients from 2004-2012, Dalwadi et al. mentioned SBRT in the introduction, but no specific analysis of SBRT was reported in the manuscript (30). However, the study did confirm that minority patients were less likely to not undergo local treatment and surgery. Compared to $11 \%$ of White patients, $18 \%$ of Black patients did not receive any treatment $(\mathrm{P}<0.001)$. While $67 \%$ of Whites received surgery, only $56 \%$ of Blacks and $58 \%$ of American Indians received surgery $(\mathrm{P}<0.001)$. Minority patients also had worse survival rates compared to White patients; the two-year cancer-specific survival for Blacks and American Indians was $76 \%$ and $73 \%$, respectively, compared to $79 \%$ for Whites $(\mathrm{P}<0.001)$. Furthermore, the median survival for Blacks and American Indians was 80 months and 49 months, respectively, in contrast to 107 months for Whites $(\mathrm{P}<0.001)$. However, on multivariate analysis, adjusting for treatment (surgery, radiation or both), cancer-specific survival for Blacks (aHR 0.98; $\mathrm{P}=0.3847$ ) and American Indians (aHR 1.33; $\mathrm{P}=0.0194)$ was not significantly different compared to Whites. 
One putative reason for the discrepancy in survival is that Black patients might be receiving less aggressive treatment (27). Lin et al. showed that Black patients were less likely to receive stage-appropriate treatment than White patients (31). Stageappropriate treatment was defined by the study as receiving the recommended lung cancer treatment within 1 year of diagnosis. The authors concluded that cultural factors (such as negative treatment beliefs, fatalism, and medical mistrust) could explain up to $30 \%$ of the difference in lung cancer care. This study only included patients from four medical centers in New York City, and may therefore not be generalizable to the patient population across the United States. Nevertheless, black and Hispanic patients were found to be more likely to hold fatalistic views about lung cancer and more likely to have misperceptions about the safety of treatment than white patients in at least one other study (10). Moreover, another study has found that between 2004 and 2016, 1,359 (0.98\%) out of 138,143 patients with NSCLC chose SBRT over recommended surgery. The percentage has been increasing from $0.1 \%$ in 2004 to $1.7 \%$ in 2016 . The same study also showed that Black patients are more likely to prefer SBRT over surgery than White patients (OR 1.50, 95\% CI, 1.231.83 ; $\mathrm{P}<0.01)(32)$. These factors may lead to delays in followup and non-compliance with staging work-up and treatment. Indeed, black patients have been shown to have a statistically significant longer median time to treatment for all lung cancer treatment modalities. In a retrospective study with 119,184 Stage I NSCLC patients diagnosed from 2008-2013, Holmes et al. found that overall $34 \%$ of Black patients had treatment initiation eight or more weeks after diagnosis, vs. $24 \%$ of White patients $(\mathrm{P}<0.001)(25)$. Specifically, the median time between diagnosis to first SBRT treatment for Black patients was 66 vs. 55 days for White patients $(\mathrm{P}<0.001)$. Similar to Corso et al. and Koshy et al., Holmes et al. also confirmed that Black patients were less likely to receive SBRT and more likely to receive CFRT.

To conclude, multiple studies have demonstrated that minority patients are less likely to receive standard of care treatment, including surgery and SBRT, compared to White patients. This disparity in receiving appropriate treatment was associated with worse survival outcomes in Blacks receiving radiation (adjusting for SBRT $v s$. CFRT) on multivariate analysis (29), but it has not been shown if decreased rates of surgery account for worsened survival in minority patients. Further investigation needs to be conducted to determine the extent to which disparities in treatment lead to survival disparities by race and ethnicity. Moreover, there is some concern that racial disparities in SBRT receipt are increasing with time. Future studies on more recent data should be performed to determine whether this divide is worsening further, with the ultimate goal of understanding and mitigating reasons for this emerging disparity.

\section{Income, education, and geographic location associated with SBRT accessibility}

In Corso et al., lower household income and education level were correlated with lower rates of receiving SBRT and higher rates of receiving CFRT or no treatment (27). In addition to income and education, there appears to be a regional disparity to SBRT as well. In a retrospective study of 340 NSCLC patients who received radiation therapy in 2006-2007, Rengan et al. found that SBRT was less frequently used at facilities located in lower socioeconomic regions (defined by zip code) (28). For the treatment of Stage I NSCLC, SBRT was utilized for $46.8 \%$ of patients who lived in regions where the unemployment rate was below the national median, but only for $14.8 \%$ of patients in regions where the unemployment rate was above the median. It is important to note that even though this study examined 45 diverse facilities across the United States, only 340 patients with NSCLC were studied. Nonetheless, another study further supports the notion that there is a regional barrier to accessing SBRT treatment. Koshy et al. found that SBRT was more likely to be used in academic research centers and high-volume facilities compared to community cancers centers and low-volume facilities (26). Use of SBRT, CFRT, and no treatment was $25 \%, 28 \%$, and $46 \%$, respectively, for patients treated in community cancer centers compared to $68 \%, 11 \%$, and $21 \%$ for patients treated in academic centers $(\mathrm{P}<0.001)$. In addition, Haque et al. intended to evaluate the difference in efficacy between SBRT and CFRT for early-stage NSCLC, but also reported similar findings (29). They found that SBRT was utilized less often in patients with lower incomes, in urban locations (compared to metropolitan), and at non-academic centers.

In other studies on early-stage NSCLC but not focused on SBRT, it has been demonstrated that lower education attainment and income levels were associated with increased lung cancer incidence $(4,33)$. For example, lung cancer incidence was much higher in individuals with less than a high school education compared to college graduates (71.6 vs. 35.9 respectively per 100,000 women; 166.6 vs. 57.6 per 100,000 men) (1). The same article suggested that smoking could explain some of the discrepancy in 
lung cancer incidence. Individuals with lower education levels were more likely to smoke and less likely to quit. In 2012, smoking prevalence for individuals with a $9-11^{\text {th }}$ grade education was $32.1 \%$, whereas it was $9.1 \%$ in college graduates (1). In addition, $68.0 \%$ of smokers with less than a high school education were interested in quitting compared to $73.3 \%$ among those with a undergraduate degree (34).

Individuals with lower SES also appear to have worse clinical outcomes in early-stage NSCLC. SES is typically evaluated in two ways: on an individual level (based on patient information) or on an area-based level (calculated using zip code). In a meta-analysis of 94 studies, Finke et al. found that both metrics were associated with worse lung cancer survival (35). Low individual income but not education level was associated with worse prognosis in this study. In comparison, areabased studies indicated that both lower income and education level were correlated with a worse outcome. The same study further revealed that survival rates were positively correlated with SES for both individual and area-based measures. Similar studies performed by Erhunmwunsee et $a l$. and Johnson et al. found that patients who lived in areas with lower median income and education level had worse mortality in both early- and late-stage NSCLC $(9,36)$.

It is highly concerning that individuals with lower SES have both higher rates of lung cancer and worse clinical outcomes. This review has identified further inequity with these patients also being less likely to receive SBRT, one of the standard-of-care treatments for early-stage lung cancer. One potential reason could be that patients with lower SES do not have access to healthcare facilities with more recent technology, and are therefore unable to receive appropriate lung cancer treatments such as SBRT. While SBRT is now a relatively common technique offered by many academic centers and major metropolitan areas, its use is not yet universal across the country, and access may be limited by regional availability and community resources (13). Therefore, these patients might receive no treatment or CFRT. Forgoing treatment for Stage I NSCLC is usually not recommended due to poor median survival with untreated disease, ranging from 9 to 14 months (37). In addition, treatment outcomes after CFRT are generally inferior to SBRT and surgery. Five-year survival after CFRT is between $15 \%$ to $39 \%$, compared to $41 \%$ for SBRT and $66 \%$ for lobectomy $(38,39)$.

\section{Summary}

Studies on the association between SBRT, race, and socioeconomic factors have been limited in number and scope, and mainly use the NCDB dataset. The paucity of studies is likely due to the fairly new advent of SBRT; this is evident in that all of the identified studies were published after 2014. Nonetheless, the six studies showed how race factors into disparities in SBRT treatment, and how variation in income, education, and geographic location (defined by zip code) affect receipt of SBRT. Overall, this review found that minority patients, especially Blacks, were less likely to receive SBRT for early-stage NSCLC in the United States compared to White patients, even after adjusting for comorbidities, insurance status, and cancer stage. This might contribute to the previously identified decrement in prognosis for minority patients with earlystage NSCLC. Some of the differences in treatment could be explained by cultural factors. In addition, patients with low income and education levels, and from nonmetropolitan areas, were less likely to receive SBRT. These factors are also correlated with worse clinical outcomes in other studies not specifically focused on SBRT.

Limitations to the reviewed studies include their retrospective design; this leads to inherent reporting/ selection bias or coding errors. The most recent year included in any of the studies was 2015, and as such, updated analyses with newer data would be helpful in determining the scope and extent of ongoing disparities. Most of the studies were conducted on similar NCDB datasets spanning the years 2003-2015, and thus did not include non-accredited hospitals. This could have resulted in underrepresentation of certain demographics of patients. Some variables, such as quality of life or treatment toxicities, were also not captured in the database and thus could not be studied. Furthermore, most of the studies focused on Stage I NSCLC only. Yan et al. found that there has been an increase in the use of SBRT in Stage II NSCLC, namely in larger node-negative tumors (17). However, the authors did not find a clear association between SBRT, race, and socioeconomic factors such as income or education, likely due to smaller numbers of patients receiving SBRT for Stage II disease. More studies should be conducted to investigate the impact of socioeconomic factors on SBRT use in Stage II NSCLC as well.

SES disparities in lung cancer treatment and survival outcome have been well-documented for decades $(9,40)$. Perhaps not surprisingly, it appears that similar disparities exist with the newer treatment option of SBRT, from access and treatment to clinical outcomes. Providers and healthcare delivery systems should aim to achieve equal 
access to SBRT in addition to other appropriate cancer therapies. Specifically, for lung SBRT, all patients with early-stage NSCLC should be evaluated by both surgical and radiation oncologists to consider all treatment options, and increasing public education about these treatments should be prioritized. It is crucial to improve the number of facilities that offer lung SBRT. The latest study on SBRT prevalence conducted in 2013, showed that only $54 \%$ of radiation oncologists in the United States reported using SBRT for lung cancer treatment (41). Oncology societies and training programs should increase awareness of SES disparities in cancer treatment delivery and outcomes. Lastly, future studies are needed to better understand the challenges and needs of underserved patients, and access to care initiatives must be prioritized to mitigate and eliminate disparities to the maximal extent possible.

\section{Acknowledgments}

Funding: None.

\section{Footnote}

Provenance and Peer Review: This article was commissioned by the Guest Editors (Virginia Litle and Kei Suzuki) for the series "Socioeconomic Disparities in the Treatment of Thoracic Malignancies" published in Fournal of Thoracic Disease. The article has undergone external peer review.

Reporting Checklist: The authors have completed the Narrative Review Reporting Checklist. Available at: http:// dx.doi.org/10.21037/jtd-20-3199

Conflicts of Interest: Both authors have completed the ICMJE uniform disclosure form (available at http://dx.doi. org/10.21037/jtd-20-3199). The series "Socioeconomic Disparities in the Treatment of Thoracic Malignancies" was commissioned by the editorial office without any funding or sponsorship. Dr. Mak reports personal fees from Merck, outside the submitted work. The authors have no other conflicts of interest to declare.

Ethical Statement: The authors are accountable for all aspects of the work in ensuring that questions related to the accuracy or integrity of any part of the work are appropriately investigated and resolved.

Open Access Statement: This is an Open Access article distributed in accordance with the Creative Commons Attribution-NonCommercial-NoDerivs 4.0 International License (CC BY-NC-ND 4.0), which permits the noncommercial replication and distribution of the article with the strict proviso that no changes or edits are made and the original work is properly cited (including links to both the formal publication through the relevant DOI and the license). See: https://creativecommons.org/licenses/by-nc-nd/4.0/.

\section{References}

1. Torre LA, Siegel RL, Jemal A. Lung cancer statistics. Adv Exp Med Biol 2016;893:1-19.

2. Siegel RL, Miller KD, Jemal A. Cancer statistics, 2020. CA Cancer J Clin 2020;70:7-30.

3. Hovanec J, Siemiatycki J, Conway DI, et al. Lung cancer and socioeconomic status in a pooled analysis of casecontrol studies. PLoS One 2018;13:e0192999.

4. Sidorchuk A, Agardh EE, Aremu O, et al. Socioeconomic differences in lung cancer incidence: A systematic review and meta-analysis. Cancer Causes Control 2009;20:459-71.

5. Alberg AJ, Ford JG, Samet JM. Epidemiology of lung cancer: ACCP evidence-based clinical practice guidelines (2nd edition). Chest 2007;132:29S-55S.

6. van Loon AJM, Van Den Brandt PA, Burg J, et al. Differences in Cancer Incidence and Mortality Among Socio-Economic Groups. Scand J Soc Med 1995;23:110-20.

7. Singh GK, Williams SD, Siahpush M, et al. Socioeconomic, rural- urban, and racial inequalities in US cancer mortality: Part I-All cancers and lung cancer and part II-Colorectal, prostate, breast, and cervical cancers. J Cancer Epidemiol 2011;2011:107497.

8. Galobardes B, Lynch JW, Smith GD. Childhood socioeconomic circumstances and cause-specific mortality in adulthood: Systematic review and interpretation. Epidemiol Rev 2004;26:7-21.

9. Erhunmwunsee L, Joshi MBM, Conlon DH, et al. Neighborhood-level socioeconomic determinants impact outcomes in nonsmall cell lung cancer patients in the Southeastern United States. Cancer 2012;118:5117-23.

10. Jonnalagadda S, Lin JJ, Nelson JE, et al. Racial and ethnic differences in beliefs about lung cancer care. Chest 2012;142:1251-8.

11. Hardy D, Liu CC, Xia R, et al. Racial disparities and treatment trends in a large cohort of elderly black and white patients with nonsmall cell lung cancer. Cancer 2009;115:2199-211. 
12. Siegel R, Naishadham D, Jemal A. Cancer statistics, 2013. CA Cancer J Clin 2013;63:11-30.

13. Pan H, Simpson DR, Mell LK, et al. A survey of stereotactic body radiotherapy use in the United States. Cancer 2011;117:4566-72.

14. Corso CD, Park HS, Moreno AC, et al. Stage I Lung SBRT Clinical Practice Patterns. Am J Clin Oncol 2017;40:358-61.

15. Zhang B, Zhu F, Ma X, et al. Matched-pair comparisons of stereotactic body radiotherapy (SBRT) versus surgery for the treatment of early stage non-small cell lung cancer: A systematic review and meta-analysis. Radiother Oncol 2014;112:250-5.

16. Yan SX, Qureshi MM, Dyer M, et al. Stereotactic body radiation therapy with higher biologically effective dose is associated with improved survival in stage II non-small cell lung cancer. Lung Cancer 2019;131:147-53.

17. Yan SX, Qureshi MM, Suzuki K, et al. Definitive treatment patterns and survival in stage II non-small cell lung cancer. Lung Cancer 2018;124:135-42.

18. Potters L, Kavanagh B, Galvin JM, et al. American Society for Therapeutic Radiology and Oncology (ASTRO) and American College of Radiology (ACR) Practice Guideline for the Performance of Stereotactic Body Radiation Therapy. Int J Radiat Oncol Biol Phys 2010;76:326-32.

19. Rubio C, Morera R, Hernando O, et al. Extracranial stereotactic body radiotherapy. Review of main SBRT features and indications in primary tumors. Rep Pract Oncol Radiother 2013;18:387-96.

20. Timmerman R, Paulus R, Galvin J, et al. Stereotactic body radiation therapy for inoperable early stage lung cancer. JAMA 2010;303:1070-6.

21. Fakiris AJ, McGarry RC, Yiannoutsos CT, et al. Stereotactic Body Radiation Therapy for Early-Stage Non-Small-Cell Lung Carcinoma: Four-Year Results of a Prospective Phase II Study. Int J Radiat Oncol Biol Phys 2009; 75:677-82.

22. Senthi S, Lagerwaard FJ, Haasbeek CJA, et al. Patterns of disease recurrence after stereotactic ablative radiotherapy for early stage non-small-cell lung cancer: A retrospective analysis. Lancet Oncol 2012;13:802-9.

23. Palma DA, Senan S. Early-stage non-small cell lung cancer in elderly patients: Should stereotactic radiation therapy be the standard of care? Int J Radiat Oncol Biol Phys 2012;84:1058-9.

24. Forrest LF, Adams J, Wareham H, et al. Socioeconomic Inequalities in Lung Cancer Treatment: Systematic Review and Meta-Analysis. PLoS Med 2013;10:e1001376.
25. Holmes JA, Chen RC. Racial disparities in time from diagnosis to treatment for stage I non-small cell lung cancer. JNCI Cancer Spectr 2018;2:pky007.

26. Koshy M, Malik R, Spiotto M, et al. Disparities in treatment of patients with inoperable stage I non-small cell lung cancer: A population-based analysis. J Thorac Oncol 2015;10:264-71.

27. Corso CD, Park HS, Kim AW, et al. Racial disparities in the use of SBRT for treating early-stage lung cancer. Lung Cancer 2015;89:133-8.

28. Rengan R, Ho A, Owen JB, et al. Impact of sociodemographic factors on the radiotherapeutic management of lung cancer: Results of a quality research in radiation oncology survey. Pract Radiat Oncol 2014;4:e167-79.

29. Haque W, Verma V, Polamraju P, et al. Stereotactic body radiation therapy versus conventionally fractionated radiation therapy for early stage non-small cell lung cancer. Radiother Oncol 2018;129:264-9.

30. Dalwadi SM, Lewis GD, Bernicker EH, et al. Disparities in the Treatment and Outcome of Stage I Non-SmallCell Lung Cancer in the 21st Century. Clin Lung Cancer 2019;20:194-200.

31. Lin JJ, Mhango G, Wall MM, et al. Cultural factors associated with racial disparities in lung cancer care. Ann Am Thorac Soc 2014;11:489-95.

32. Khorfan R, Kruser TJ, Coughlin JM, et al. Survival of Primary Stereotactic Body Radiation Therapy Compared With Surgery for Operable Stage I/II Non-small Cell Lung Cancer. Ann Thorac Surg 2020;110:228-34.

33. de Groot PM, Wu CC, Carter BW, et al. The epidemiology of lung cancer. Transl Lung Cancer Res 2018;7:220-33.

34. Babb S, Malarcher A, Schauer G, et al. Quitting Smoking Among Adults — United States, 2000-2015. MMWR Morb Mortal Wkly Rep 2017;65:1457-64.

35. Finke I, Behrens G, Weisser L, et al. Socioeconomic differences and lung cancer survival-systematic review and meta-analysis. Front Oncol 2018;8:536.

36. Johnson AM, Hines RB, Johnson JA, et al. Treatment and survival disparities in lung cancer: The effect of social environment and place of residence. Lung Cancer 2014;83:401-7.

37. Raz DJ, Zell JA, Ou SHI, et al. Natural history of stage I non-small cell lung cancer: Implications for early detection. Chest 2007;132:193-9.

38. Zheng X, Schipper M, Kidwell K, et al. Clinical Investigation Survival Outcome After Stereotactic Body 
Radiation Therapy and Surgery for Stage I Non-Small Cell Lung Cancer: A Meta-Analysis Radiation Oncology. Int J Radiat Oncol Biol Phys 2014;90:603-11.

39. Jeremic B, Classen J, Bamberg M. Radiotherapy alone in technically operable, medically inoperable, early-stage (I/ II) non-small-cell lung cancer. Int J Radiat Oncol Biol Phys 2002;54:119-30.

Cite this article as: Lin Y, Mak KS. Racial and socioeconomic disparities in the use of stereotactic body radiotherapy for treating non-small cell lung cancer: a narrative review. J Thorac Dis 2021;13(6):3764-3771. doi: 10.21037/jtd-20-3199
40. Albano JD, Ward E, Jemal A, et al. Cancer mortality in the United States by education level and race. J Natl Cancer Inst 2007;99:1384-94.

41. Pan H, Rose BS, Simpson DR, et al. Clinical practice patterns of lung stereotactic body radiation therapy in the united states: A secondary analysis. Am J Clin Oncol 2013;36:269-72. 